\title{
ORDER OUT OF CHAOS
}

\author{
MISS M. ROPER, M.C.S.P. Lecturer in Physiotherapy, Dept. of Physiotherapy, University of Cape Town \\ (Lecture delivered at the Post-Graduate Course on Therapeutic Movement, University of Cape Town, Department \\ of Physiotherapy, October 1961.)
}

\section{"And the Earth was without form and void- and the Spirit of God moved." \\ In other words order emerged from chaos.}

I am not going to tell you anything new, anything you do not already know. I am going to ask you, with me, to think over some of the basic principles we all learnt as students. I humbly suggest that in the rush and bustle of our clinical work we may have forgotten and discarded some useful and important concepts-or at least we have not developed and used them with all the thought and skill in our power.

The definitions of "move" in Chamber's Dictionary are many-here are some of them. "To impel, to excite to action, to persuade, to instigate, to arouse, to live one's life". All germane to what we think about and how we act in teaching our patients to move. Perhaps the most pertinent of all, the last one "to live one's life".

As Physiotherapists isn't our most important aim in all our treatments to restore "order" in movement that has become "chaotic"-chaotic due to pain, limited range, loss of muscle power and neuro-muscular co-ordination?

We have heard from Professor Wells and Professor Stammers something of the anatomical physiological background of the ordered movement, and from Professor Allen a challenging lecture on its importance. But is not this restoration of ordered movement our own greatest contribution to rehabilitation, provided it takes into account the "whole person".

In the creation of the Universe, and in it this World, is not man the highest created being and is not his gift of free will the most precious gift with which he has been endowed? So in our humble efforts to restore order to a disorganised chaotic motor system, should not our foremost aim (by arousing, exciting to action, and persuading) be to enlist the patient's free will, and help him to direct it towards his

(Continted from opposite page)

linked together by a complex system of interconnections, by means of which, it is assumed, the cerebral cortex establishes a predominance over the other components of the brain. Consequently the results of anatomical and physiological studies on simpler type of animal brain cannot necessarily be applied to the much more complexly organised human brain.

\section{General:}

\section{REFERENCES}

Barnett, C. H., Davies, D.V., and MacConaill, M. A. (1961. Synovial Joints. Their Structure and Mechanics. London: Longmans, Green and Co. xi + 304 pp.

Chusid, J. G. and McDonald, J. T. (1960). Correlative Neuroanatomy and Functional Neurology. 10th ed. Los Altos, Cal.: Lange Medical Publications, $360 \mathrm{pp}$.

le Gros Clark, W. E. (1952). The Tissues of the Body. 3rd ed. Oxford: Clarendon Press, xi $+407 \mathrm{pp}$.

\section{Particular:}

Basmajian, J. V. (1959). "Spurt" and "shunt" muscles: an elecromyographic confirmation. J. Anat. Lond., Vol. 93, pp. 551-3.

Grant, J. C. B. (1958). A Method of Anatomy. 6th ed. Baltimore: Williams and Wilkins. xxv $+879 \mathrm{pp}$

MacConaill, M. A. (1949). The movements of bones and joints, 2. Function of the musculature. J. Bone Jt. Surg. Vol. 31B, pp. 100-104.

Martin, C. P. (1933-34). A comparison of the joints of the arm and leg and the significance of the structural differences between them. J. Anat. Lond., Vol. 68, pp. 511-520. return to normal ordered bodily function-to live his own life? This brings me to my first point:

Bring in the patient-not just literally but in every sense of the word. Psychologically and physiologically he will benefit most if he co-operates as fully as possible in his rehabilitation programme.

Psychologically how dangerous dependence on another's efforts can be. How restricting to the whole concept of rehabilitation is just the alleviation of pain or even, to take an extreme example, maintenance of muscle and joint by electrical means and passive movements only: passive movements performed by the physiotherapist without making the patient "think" the movement as it is done for him. This thinking the movement at once brings him into the picture, and as we all know is physiological commonsense in that it helps to maintain the memory pattern. The idea of that movement is kept alive by making the patient realise the afferents from muscle tendon and joint as the pattern is performed. Psychologically it is common sense as he is automatically participating in this initial activity and is therefore realising that he has to do something himself to effect his own cure.

Media for Movement-Water or dry land. Water will be dealt with by Mr. Nicol.

Manual or Mechanical-Dry land treatments by movement will include the use of manual and mechanical assistance or resistance. Both have advantages and disadvantages as you very well know. We are all aware of the danger of using mechanical aids to movement, meaning specifically mechanical assistance with springs or weights. We know the danger of over-stretching tissues if the aid cannot be fully controlled, or the danger of repetitive irritating movements using suspension or bilateral pulleys-yet in selected cases they can be most valuable as they may provide a means of enabling the patient to work on his own, i.e. without the obvious assistance of the physiotherapist, when without the sling or pulley or spring he could do little or nothing at all.

Manual assistance or resistance is sometimes better than mechanical means. It is sensitive and adaptable to the changing states of tension, spasm or inco-ordination in the neuro-muscular mechanism, and can therefore more readily be adapted to meet these changes. On the other hand too much manual handling can be psychologically undesirable, leading to dependence of the patient on the physiotherapist.

Mechanical means can be arranged and worked by the patient himself; even at home. They are time-saving for the physiotherapist, whereas manual techniques are timeconsuming. Perhaps the greatest danger of all in using mechanical apparatus is that it can become too automatic and lack the essence of truly "live movement". But again, if scientifically arranged with due regard to mechanical and physiological principles, the great advantage of using weights, for example, is that progress can be graded accurately and the patient can often treat himself at home.

Group of Individual-Which will suit this patient best?

Quite likely he will benefit by some of each. We are apt to think we cannot give group treatments if we have no gymnasium. I sometimes think a gymnasium is a bad thing in a department. It tends to be set apart as a separate entity rather than being the central core of the whole set-up. Actually a round department with cubicles at the periphery and central space with some exercise equipment could be a very good plan! However, if we are really group minded. group treatments can be given, even if the department or clinic will only hold two patients and the physiotherapist. Organisation of like type of cases at the same time for other 
treatments will take thought and time, but in the long run will save time, as each patient will have more treatment for less expenditure of the physiotherapist's time. The obvious danger is, of course, to go to the other extreme and "put all the knees together" to save time - when all the knees may not require the same type of treatment, and therefore no one gets what he really needs most. But the psychological effect of group treatment can be very beneficial in helping the patient to adapt himself to live in a community with a partial disability.

\section{Treatment Time}

Physiotherapist patient time is so precious. I often think we neglect this most important part of our treatmentparticularly important in a country like this where distances are so great. Do we pay enough attention to this home instruction which is so essential in the "training", a better word than treatment, of our patients. Here I think you will agree we must be particularly careful to be specific. For example, do we take a whole "so-called treatment time" to really teach the patient what he has to do, and instil into him the importance of his co-operation. I feel sure if we did in many instances our departments would not be so full, and patients would get well more quickly. Here I have a particular "bee in my bonnet" about the common instruction one reads about exercise for five minutes once every hour! Isn't it better to allow the patient to occupy himself as normally as possible and to do his "training" say before meals, when he has in any case a break from whatever activity he may be following?

\section{TRAINING, INSTRUCTION, TEACHING}

We are all teachers, not just those of us who have taken a training with the aim of trying to make us able to teach others to be physiotherapists.

To teach we must know what to teach and how to teach it. Therefore, before we start we must have a clear picture of the patient's needs and what he should be taught: therefore, we must have as complete an understanding of the condition as possible.

There is some disorder, dysfunction, call it what you will, due to pain, stiffness, weakness, inco-ordination-in other words chaotic movement. We have to devise a pattern, a sequence, a curriculum that will enlist the patient's free will and co-operation, in order that we may help him to restore his movement to order. We must therefore know as precisely as possible what is the reason for this disorder before we can begin to plan our programme of training.

Granted we must have an adequate diagnosis from our Medical Directors-but having this it is our job to find out the details of the pdin, limited movement, spasm, contracture, weakness, and so on.

\section{Assessment of the Condition}

Assessment of the condition is obviously essential before this plan can be made. I submit that careful assessment before treatment is started, even if it takes the whole of the first treatment period, will save time in the long run. This assessment should be as accurate as possible and should be repeated at intervals, even if again a treatment period is taken to do so. A check can then be made as to whether progress is really being made.

Accurate Records

This comparison can only be made if accurate records are kept. These are probably the most thorny problems of all. How to strike the balance between too much writing and not enough information. Here I think specific charts (similar in principle to the muscle charts we all use) are helpful. Probably each unit should devise their own so that all are familiar with the layout, including the medical officers in charge of the patients. Charts for joint range and function are particularly helpful here as a tick or figure is all that is needed. Time is certainly saved here if colleagues have to take over a treatment, specially in my case as I know how illegible my writing can be! Here there are one or two points I think we should strive to note with some degree of accuracy: actual ranges of movement measured by a goniometer or assessed as two-thirds or one-half, rather than the vague phrase "movements limited", then a bit later "movements improving". For the severely disabled functional charts are a great help as all that is required is a symbol against an activity-can dress himself, walk, etc., with assistance, unaided, etc. All this will be of little avail unless we have the full co-operation our work requires from the doctors in charge of our cases: without that we are in a bad way.

Aims of Movement

Having now a reasonably clear picture of the disability -is the limitation due to spasm? Is the joint irritable? Is it due to muscle weakness or inco-ordination?- - and so on-we must decide what are the main aims of movement and how can they best be achieved. For example if mobility be required then movements should be chosen that require minimal effort but can be performed quickly, recruiting momentum to help. If power be lacking then maximum effort for a short time must be exerted. To train endurance, less effort over a longer period will be more efficient. For lack of co-ordination, precise and repetitive movements must be practised. What is the patient's own natural rhythm? Do we desire a localised or a group movement? If the latter what sort of movement will this patient do most naturally? These are some of the points to be borne in mind. Here 1 think we may well consider the inclusion in the table of exercise of at least one anatomical movement, one functional movement, and one recreational movement. In choosing movement let us also remember the prime movers, the synergist fixators and co-operators, as often muscle and joint can be used by thinking out movements in which muscles are brought into action in these various ways.

\section{Teaching and Learning}

Teaching and learning are dependent on each other, so in teaching we must assist the patient to learn, and to do this we need to recruit all possible afferents.

Sound: How we use out voices, the tone, the speed, the inflection. Sound often helps in helping to eradicate a limp if he is encouraged to listen to the sound of his footsteps.

Vision: Demonstrate clearly ourselves and let him watch, make him watch his own performance in a mirror, or on the sound limb if possible.

Feeling: Exteroceptive and proprioceptive-touch the spot where he should feel the pull of the muscle that should contract more fully. Make him think of the movement as he does it on his good side.

Outflow will depend so much on inflow, particularly in re-educating the fine movements of the hand, where what we feel influences so much what we do.

Then back again to home instruction, homework for him to do and most important, when he comes again, remember what we told him and praise or reprimand as the case may be.

Conclusion

To conclude, I will quote from Dr. Tegner's foreword to M. Dena Gardiner's book "The Principles of Exercise Therapy":

"Physiotherapy is no static art-passive treatments of inert patients making no effort to help themselves are regarded as possibly prolonging rather than cutting short invalidism. Yet in spite of ... (discarding many passive methods) more patients are referred for physiotherapy than ever before. The gospel of activity has been widely preached and there seems little doubt that patients are reaping the benefit."

Let us therefore continue to "move" with the timesto excit to action, persuade and arouse our patients to live their lives more fully and actively.

To do so let us remember what Miss Gardiner quotes in her Preface:

"I keep six honest serving men,

(They taught me all I knew)

Their names are What and Why and When

And How and Where and Who."

Finally let us put our whole selves into this most highly skilled and difficult of all our techniques, the Teaching of Movement, so that order out of chaos (here in all reverence I paraphrase the end of the book from which I quoted at the beginning) may "surely-come quickly". 